\title{
FMRP unida por um semestre melhor: narrativas de um pacto que celebra valores humanos e compromissos coletivos durante a pandemia da covid-19
}

\author{
FMRP unified for a better semester: narratives of a Pact that celebrates \\ human values and collective commitments during the Covid-19 pandemic
}

\author{
Maria Paula Panúncio-Pinto ${ }^{1}$ (D) Rodrigo Humberto Flauzino ${ }^{2}$ (D), Victor Evangelista de Faria Ferraz ${ }^{3}$ (D), \\ Valdes Roberto Bollela4 (D)
}

\begin{abstract}
RESUMO
A pandemia da COVID-19 impactou a educação superior de diversas formas, demandando criatividade e resiliência no seu enfrentamento. Além dos novos desafios, o cenário induzido pela crise sanitária também agudizou problemas pré-existentes, principalmente no que se refere às relações humanas dentro da universidade, à equidade no acesso a recursos educacionais e à capacitação para o desenvolvimento profissional, qualidade de vida e o cuidado com as pessoas, entre tantos outros desafios. Nesse contexto, em busca de respostas para os problemas apresentados, diferentes centros e comissões da Faculdade de Medicina de Ribeirão Preto da Universidade de São Paulo (FMRP-USP) se uniram e propuseram a celebração do Pacto "FMRP: UNIDA POR UM SEMESTRE MELHOR". O Pacto foi proposto para reafirmar os valores da instituição, fortalecer as relações e a rede de suporte às pessoas e aos processos, minimizar o estresse e o impacto na saúde e bem-estar de estudantes, funcionários e professores. 0 objetivo deste relato é apresentar os termos e condições que tornaram o Pacto possível, como estratégias utilizadas para sua execução, ações integradas de diferentes setores, comunicação qualificada visando responder às necessidades da comunidade acadêmica. O pacto promoveu ações para garantir acesso a recursos para ensino e aprendizagem, capacitação profissional e cuidado nas relações interpessoais e entre os diferentes setores da instituição. O Pacto nasceu no contexto da pandemia e chamou atenção para a necessidade constante de aprimorarmos nossas relações, de investir no diálogo e na integração. Já não se trata de ações para "um semestre melhor", mas de compromissos e valores que reafirmamos e devem seguir conosco seja qual for o contexto e situação.
\end{abstract}

Palavras-chave: Educação superior; Crise sanitária; Pandemia; Ensino remoto; Estratégias de enfrentamento; Covid-19

\begin{abstract}
:
The COVID-19 pandemic impacts on higher education in several ways, demanding creativity, and resilience in facing it. In addition to the new challenges, the scenario induced by the health crisis has also aggravated pre-existing problems, especially with regard to human relations within the university, equity in access to educational resources and training for professional development, quality of life and caring for people, among many other challenges. In this context, in search for answers to the challenges presented, different FMRP centers and committees came together and proposed the celebration of the Pact "FMRP: UNIFIED FOR A BETTER SEMESTER". The Pact was proposed to reaffirm the institution's values, strengthen relationships and support network, minimize stress and the impact of this new reality on the health and well-being of students, staff and teachers. The purpose of this report is to present the terms and conditions that made the Pact possible, the strategies used for its execution, with integrated actions from different sectors, qualified communication, responding to the needs of the academic community. The purpose of this report is to present the terms and conditions that made the Pact possible, the strategies used for its execution, with integrated actions from different sectors, qualified communication, responding to the needs
\end{abstract}

\footnotetext{
${ }^{1}$ Universidade de São Paulo, Faculdade de Medicina de Ribeirão Preto, Departamento de Ciências da Saúde, Ribeirão Preto, SP, Brasil

2 Universidade de São Paulo, Faculdade de Medicina de Ribeirão Preto, Centro de Apoio Educacional e Psicológico, Ribeirão Preto, SP, Brasil

${ }^{3}$ Universidade de São Paulo, Faculdade de Medicina de Ribeirão Preto, Departamento de Genética, Ribeirão Preto, SP, Brasil

${ }^{4}$ Universidade de São Paulo, Faculdade de Medicina de Ribeirão Preto, Departamento de Clínica Médica, Ribeirão Preto, SP, Brasil
} 
of the academic community. The pact has enabled actions to guarantee access to resources for teaching and learning, professional training and care, in addition to strengthening interpersonal relationships and between different sectors of the institution. The Pact was born in the context of the pandemic, but it calls our attention to the constant need to improve our relations, to invest in dialogue and integration. We are no longer dealing with actions for "a better semester", but with commitments and values that we will continue to reaffirm.

Keywords: Higher education; Health crisis; Pandemic; Remote education; Coping strategies; Covid-19

\section{MENSAGENS PRINCIPAIS}

- Os contextos educacionais foram impactados fortemente pela pandemia em todos os níveis. Sustentar seu funcionamento na educação superior para as profissões da saúde, com as adaptações possíveis, exigiu o esforço coletivo de toda a comunidade acadêmica.

- O Pacto reflete o reconhecimento de que é preciso cuidar de estudantes, docentes e funcionários e acolher angústias, oferecer escuta qualificada e espaços de trocas. Também é preciso promover o desenvolvimento de recursos para lidar com a educação e com o trabalho remotos, que são pilares importantes para um melhor enfretamento da crise sanitária.

- O ser humano é um ser social, que precisa do outro e de constante interação para se desenvolver plenamente. Continuar apostando nessa premissa da formação do sujeito, em meio ao distanciamento social imposto e necessário, foi um desafio que fez com que a criatividade, o espírito de sobrevivência e o compromisso com a coletividade falassem mais alto.

- A criação de um Pacto que reafirma valores humanos para atravessar a Pandemia com mais segurança e saúde, aponta para a missão maior da universidade, que é produzir e disseminar o conhecimento, ao mesmo tempo que oferece uma educação integral que conecte as pessoas à importância de criar e fortalecer relações mais solidárias e cooperativas.

\section{CONTEXTO/INTRODUÇÃO}

A nova realidade imposta pela Pandemia de Covid-19 tem desafiado a resistência e a criatividade de todas as pessoas, em especial de atores do cenário educacional, em todos os níveis.

Desde meados de março de 2020, o cotidiano acadêmico foi totalmente transformado pelas medidas de distanciamento social impostas abruptamente, em resposta à grave crise sanitária que então se desenhava.

O primeiro semestre mal havia começado, e as aulas presenciais foram suspensas a partir de 17 de março, com base no comunicado1 do Conselho de Reitores das Universidades Estaduais Paulista (CRUESP), considerando as recomendações do Ministério da Saúde, da Secretaria de Estado da Saúde e do Governo do Estado de São Paulo².

$\mathrm{Na}$ Universidade de São Paulo (USP), muitos comunicados da Reitoria passaram a chegar em intervalos curtos de tempo, com novas medidas e recomendações, com o avanço da epidemia. Fomos chamados a manter as atividades de ensino, pesquisa, assistência, gestão e todas as demais ações sob nossa responsabilidade $^{3}$, agora adaptadas, devido ao necessário distanciamento social. A transformação das atividades acadêmicas presenciais em remotas ${ }^{4}$, e a necessidade de ajustes a este novo cenário, provocou mudanças nas rotinas e nos modos de viver, estudar e trabalhar, afetando nossos fazeres cotidianos.

Nesse contexto, a comunidade da Faculdade de Medicina de Ribeirão Preto (FMRP-USP) estudantes, funcionários e docentes - passou a enfrentar o desafio de ajustar-se a essa realidade, que impactou de forma importante o primeiro semestre letivo de 2020.

Muitos desafios surgiram para todos, nesse processo de reorganização do ensino e do trabaIho de forma remota, na passagem de uma lógica presencial para uma nova dinâmica das atividades: trabalho e/ou ensino remoto. 
Pelo inusitado da situação e pela absoluta falta de tempo para coordenar uma resposta, as alternativas para seguir em frente foram sendo encontradas individualmente, geralmente de forma pouco integrada, em cada setor, a partir das demandas específicas da área, um dia após o outro.

Com o desenrolar do primeiro semestre de 2020, a ausência de perspectiva para a retomada das atividades presenciais e a demanda constante por novas habilidades - estudar, ensinar, aprender, avaliar, administrar, pesquisar, cuidar de si e do outro - evidenciaram fragilidades que colocavam sob estado de atenção pessoas, processos e resultados, e que reclamavam estratégias para seu enfrentamento.

Os pedidos de socorro começaram a surgir nas diferentes instâncias da FMRP, vindos de estudantes, professores e funcionários. Ao mesmo tempo, iniciativas diversas foram propostas para responder aos desafios, e todos fomos adquirindo recursos para estar juntos, manter a comunicação, mesmo que remotamente: reuniões virtuais de colegiados, centros e lideranças de professores e estudantes; divulgação de estratégias e ferramentas disponíveis para atividades à distância; comunicados e recomendações à comunidade. As situações-problema surgiam e iam sendo abordadas, com os recursos que cada um conseguia acessar, enquanto o semestre seguia seu curso.

À medida em que aumentavam a frequência e a intensidade das solicitações de ajuda, foi possível reconhecer um risco real para a saúde mental de todos. Começamos a perceber então, que sem uma ação integrada e coletiva, de iniciativa institucional, seria difícil assegurar condições de trabalho, estudo, manutenção dos vínculos e qualidade de vida.

As principais demandas incluíam equidade de acesso ao ensino remoto, considerando a diversidade das condições de vida dos estudantes; adaptação/atualização de estratégias de ensino e avaliação e oferta de capacitação para os professores; garantia de espaços institucionais para o diálogo; qualificação da comunicação e possibilidades para a realização das atividades técnico -administrativas pelos funcionários.
Foi necessário reconhecer que, apesar da grande disponibilidade de estratégias de tecnologia da informação, da divulgação das principais plataformas de educação à distância e da oferta de tantas outras orientações5, não estávamos familiarizados o suficiente com as atividades não presenciais, não sendo fácil fazer as melhores escolhas, para cada situação.

Com o primeiro semestre chegando ao final, sem perspectiva de retomada das atividades presenciais, algumas metas emergiram como prioritárias: melhorar a comunicação e a integração entre os diferentes setores da FMRP, visando o planejamento e a execução de ações mais articuladas e estruturadas.

Nesse contexto, nasceu a ideia de unir a comunidade, para reafirmar os valores da instituição, fortalecer as relações e a rede de suporte, minimizar o estresse e o impacto dessa nova realidade na saúde e bem estar de estudantes, funcionários e professores. Assim, a Diretoria da FMRP propôs um pacto que foi declarado na expressão: FMRP: UNIDA POR UM SEMESTRE MELHOR e convidou toda a comunidade a integrar esta iniciativa. O logo da campanha foi proposto por estudantes da faculdade e aprovado por todas as pessoas envolvidas (Figura 1 )

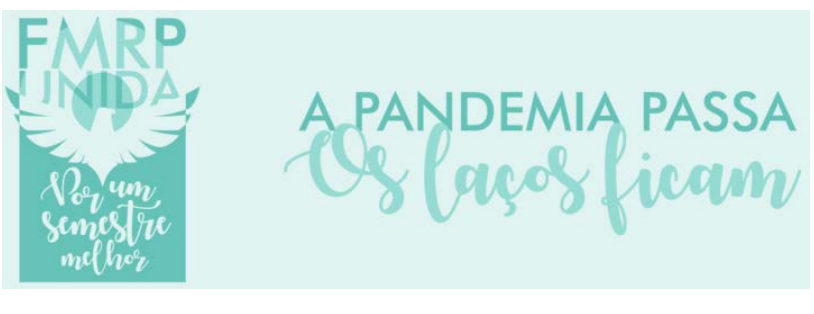

Figura 1: Logo e mensagem principal do Pacto feito pela comunidade FMRP-USP

Nosso objetivo aqui é apresentar as condições e estratégias de gestão utilizadas para integrar diferentes setores da instituição, em resposta às necessidades da comunidade acadêmica. Inicialmente, a título de contextualização, vamos contar um pouco das peculiaridades da gestão e das decisões que levaram a constituição das instâncias que tornaram possível o PACTO, para em seguida apresentar os seus termos e as ações integradas que foram realizadas. 


\section{O CONTEXTO INSTITUCIONAL QUE FAVORECEU A CELEBRAÇÃO DO PACTO}

Nos últimos cinco anos, a FMRP tem reafirmado seu compromisso com a valorização e o cuidado de seu maior patrimônio: as pessoas. Para atender a esse compromisso, a Diretoria mantém quatro instâncias assessoras, cada qual com características e atividades próprias, que atuam de maneira integrada para alcançar esse objetivo comum de "cuidar": O Centro de Apoio Educacional e Psicológico (CAEP); o Centro de Avaliação do Ensino de Graduação (CAEG); o Centro de Desenvolvimento Docente para o Ensino (CDDE) e a Comissão de Direitos Humanos (CDH).

O CAEP é o centro mais antigo, criado em 1990 em resposta à preocupação da Comissão de Graduação com a oferta de apoio/atenção aos estudantes6. O CAEP conta com equipe técnica especializada (psicologia, pedagogia e psicopedagogia), apoio administrativo e um grupo de professores que compõem seu conselho consultivo. O Centro desenvolve atividades de apoio psicológico e pedagógico aos estudantes, além de prestar suporte às atividades de ensino e pesquisa na área de educação nas profissões da saúde. Equipe técnica e grupo de consultores desenvolvem atividades de promoção da qualidade de vida e da saúde mental do estudante. Além disso, os setores de Psicologia e Educação assessoram as Comissões Coordenadoras dos sete cursos de graduação da FMRP7.

O CAEG foi criado em 2015, para oferecer subsídios à Comissão de Graduação e às Comissões Coordenadoras de Cursos no que se refere ao desenho, implementação e monitoramento dos sistemas de avaliação das disciplinas e do estudante. O Centro conta com professores representantes dos cursos de graduação, e com representante discente, e juntos operacionalizam as atividades. Em diferentes momentos conta com assessoria do CDDE e do CAEP, no desenvolvimento de suas atividades.

O CDDE foi criado em dezembro de 2016, e reflete o compromisso da FMRP com a elaboração e execução de um "Plano de Desenvolvimento Docente", investindo na formação de professores, através da oferta de atividades que os aju- dem a renovar e melhorar seu desempenho, aumentando a qualidade e a efetividade da prática educacional. As atividades são coordenadas por seu Conselho Gestor, em conjunto com seu Núcleo Docente Permanente, que é formado por 14 professores, 1 educador e 2 assistentes administrativos. Dentre as ações que são realizadas pelo CDDE, os cursos regulares de extensão, ofertados anualmente (módulo básico de educação nas profissões da saúde; oficinas temáticas curtas e módulos avançados; capacitação para o ensino em cenários da prática profissional) já receberam mais de 200 professores, preceptores de práticas da FMRP, e de fora. Muitas atividades do CDDE são realizadas em parceria com CAEP e CAEG.

A $\mathrm{CDH}$ foi criada em agosto de 2016, em consonância com o movimento mundial para o combate às desigualdades e violações de direitos humanos, para nortear as relações humanas em um ambiente plural e de respeito, promovendo o humanismo no ambiente acadêmico, com especial atenção no combate à violência interpessoal, à discriminação de gênero, raça, cor, etnia, religião, idade, classe social, orientação sexual e identidade de gênero. A Comissão é formada por representantes de professores, estudantes e funcionários. Para atingir seus objetivos a $\mathrm{CDH}$ atua em duas linhas principais: (1) Educação e sensibilização, com atividades que mantém na pauta temas importantes dos direitos e equidade, através de campanhas, eventos e divulgação de material informativo; (2) Acolhimento e manejo de denúncias sobre violação de direitos humanos na comunidade acadêmica.

A criação e fortalecimento dessas instâncias refletem uma decisão institucional de "CUIDAR": dos estudantes, dos professores, do corpo técnico administrativo, do ensino e da formação, e das relações na comunidade acadêmica.

No desenvolvimento de suas atividades, os quatro centros têm muitas interfaces, o que tem resultado na integração de suas atividades. Não é possível investir em desenvolvimento docente sem olhar para as questões de apoio aos estudantes; o suporte ao desenvolvimento acadêmico dos estudantes e profissional de professores e funcionários, não escapa à temática dos direitos humanos e da diversidade; e não é possível contribuir para o desenvolvimento de estudan- 
tes e professores, sem investir na qualidade do ensino, que sempre irá envolver atividades de avaliação (do ensino, do programa educacional e do estudante).

No cotidiano das atividades desenvolvidas no contexto da Pandemia, ao longo do primeiro semestre de 2020, demandas vindas de diferentes setores chegaram até essas quatro instâncias, lançando desafios diários à gestão. A atividade desses centros começou a gerar estratégias de enfrentamento, e nessa realidade, todos os caminhos apontavam para a integração, tanto para fazer um diagnóstico mais preciso das necessidades de estudantes, professores e funcionários, quanto para traçar um plano para responder aos desafios apresentados.

A proposta do Pacto "FMRP: Unida por um semestre melhor" nasce nesse contexto. A ideia de celebrar um pacto e de elencar uma série de compromissos que devem ser assumidos por toda a comunidade, vem do reconhecimento de que a integração requer estratégias estruturadas para acontecer e se manter, ela não acontece naturalmente, mas deve ser uma meta que se constrói a cada dia, e que depende da capacidade institucional de fomentar o diálogo e a comunicação, e de investir em estratégias de aproximação, delineando ações específicas para cada segmento, olhando para as interfaces, sem negar as singularidades.

Neste ponto cabem algumas reflexões sobre os desafios de práticas colaborativas, do trabalho em equipes e da integração.

Desde nossas primeiras experiências na escola, nos deparamos com a ideia de que somos seres sociais. Tomando uma perspectiva sócio-histórica, podemos reconhecer que nossa sobrevivência depende, de nossa capacidade para cooperar e viver em grupo. Dependemos do OUTRO para aprender, sobreviver e viver. Sabemos quem somos e nos diferenciamos como pessoas porque a convivência com o outro nos constitui $^{8}$. O outro é o mediador da aquisição de instrumentos fundamentais que nos tornam mais humanos, membros de uma espécie que compartilha símbolos, significados, rituais, crenças e sentimentos. Essa humanidade compartilhada nos reafirma como membros de um grupo: a espécie humana.
Em algumas culturas a ideia de "pertencer" a uma relação social é tão necessária e tão forte que a unidade funcional da consciência é a relação e não o indivíduo. É assim nas culturas orientais, onde o reconhecimento da interdependência entre os seres humanos leva a uma conectividade, que não se vê no ocidente ${ }^{9}$. Se para os orientais é fundamental ser agradável e cuidar do outro devido a compreensão da interdependência existente entre os seres humanos, no ocidente a competitividade é estimulada e a correta expressão de atributos individuais é mais importante que o relacionamento com o outro. Talvez por vivermos no ocidente, na ideologia da supervalorização do indivíduo, é que a integração - interprofissional, intersetorial, interdisciplinar - seja tão difícil de construir, demande esforços permanentes e ações institucionais planejadas para este fim.

Além dessas questões culturais, que podem fortalecer o individualismo e se constituir em barreiras à integração, enfrentamos também o desafio de manter o olhar da complexidade, proposto por Morin: os problemas não podem ser parcelados, pois a realidade é complexa, e não poderá ser melhor compreendida se dividida em fragmentos. Dividir a realidade em partes menores para entendê-la é uma atitude cartesiana, que só diminui as possibilidades de reflexão e ação. É reconhecendo a complexidade todo-partes que podemos avançar na solução de problemas. Complexus, "aquilo que é tecido junto"10, 11.

Quando uma instituição reconhece a necessidade de empreender esforços para manter, ao mesmo tempo, o olhar sobre o todo e sobre as partes, e de criar estratégias para a integração, começa a se estabelecer um ambiente mais seguro, que favorece o diálogo e a comunicação.

\section{OS TERMOS DO PACTO E AS AÇÕES INTEGRADAS PARA APOIAR A CO- MUNIDADE ACADÊMICA}

Tendo em vista a necessidade de qualificar a comunicação e integrar esforços para continuar seguindo em frente, os termos do Pacto reafirmam os valores da nossa instituição: equidade, tolerância, respeito nas relações interpessoais, cooperação e solidariedade. E para que ele se tor- 
ne uma REALIDADE cada pessoa, e as lideranças da FMRP-USP, se comprometem a:

- Apoiar-se mutuamente (estudantes, funcionários e professores);

- Abrir espaço para a reflexão, o diálogo e a troca de experiências;

- Favorecer uma comunicação respeitosa e qualificada;

- Promover as melhores práticas de ensino, avaliação e gestão acadêmica;

- Buscar e oferecer ajuda, reconhecendo as suas necessidades e expertises;

- Criar oportunidades para a aquisição e aprimoramento das competências necessárias para o cumprimento do nosso papel de estudantes/aprendizes e profissionais/educadores;

- Estimular, permanentemente, o desenvolvimento pessoal e profissional dos membros da nossa comunidade, em todos os espaços de trabalho e convivência, presenciais ou virtuais.

A partir desses termos, os diferentes centros e comissões da FMRP passaram a propor e desenvolver ações para apoiar a formação e o desenvolvimento profissional dos diversos segmentos da comunidade. A Tabela 1 apresenta uma síntese das ações que vêm compondo o Pacto ( Tabela 1: O Pacto na prática - ações, público-alvo e instâncias responsáveis).

\section{AÇÕES VOLTADAS PARA OS ESTU- DANTES (CAEP, CDH, CG)}

Com a suspensão das atividades presenciais, o CAEP propôs manter seus programas, projetos e atendimentos de forma remota. Os atendimentos individuais oferecidos aos estudantes de graduação (Aconselhamento Psicológico, Atendimento Psicopedagógico e Peda- gógico), passaram a ser realizados no formato on-line. Os atendimentos e atividades grupais, como oficinas temáticas (estilos de aprendizagem, organização de estudos, ansiedade escolar), rodas de conversa, grupos de reflexão e grupos do Programa de Mentoria, também foram adaptados e continuaram acontecendo de forma remota. Todo esse movimento, buscou superar a simples transposição de conteúdos e práticas do formato presencial para o remoto, através da intenção pedagógica de manter a interação entre os participantes, o acesso ao conhecimento e a recursos, as oportunidades de troca de experiências.

Além da manutenção dos atendimentos e atividades grupais, a equipe técnica do CAEP atuou na produção de conteúdo digital para apoiar os estudantes. Vídeos curtos foram divulgados em diferentes plataformas (site caep.fmrp. usp.br e canal e CAEP-FMRP-USP, no Youtube), e-mail institucional, listas de contatos dos cursos de graduação e centros estudantis, e tratam de temas como Hábitos saudáveis; Organização do Espaço e da Rotina de Estudo e como Lidar com a Ansiedade.

Com a participação de uma arte-educadora, em parceria com o pedagogo, foi ofertado um curso de difusão, especialmente pensado para estudantes de graduação da FMRP, que recebeu também estudantes de outras unidades do Campus USP Ribeirão Preto. O curso propôs, através de recursos simbólicos e da arte, conectar estudantes com sua saúde psíquica, e desta forma humanizar as relações.

Foram realizados diversos momentos de diálogo/escuta promovidos pela Comissão de Graduação e Comissões Coordenadoras de Cursos, com as representações estudantis, para ajustes finos que aconteceram ao longo do percurso, sempre com a preocupação de qualificar a comunicação, para integrar e responder aos desafios. 
Tabela 1: O Pacto na prática - ações, público-alvo e instâncias responsáveis

\begin{tabular}{|c|c|c|}
\hline PUBLICO ALVO & AÇÃO & RESPONSÁVEL \\
\hline \multirow{9}{*}{ ESTUDANTES } & Curso de difusão "Um outro CID..." de arte-educação & \multirow{8}{*}{ CAEP } \\
\hline & Aconselhamento psicológico online & \\
\hline & Orientação pedagógica/psicopedagógica online & \\
\hline & Oficina de estilos de aprendizagem online & \\
\hline & Oficina de organização de estudos online & \\
\hline & Mentoria online estendida ao ano todo & \\
\hline & $\begin{array}{l}\text { Vídeos disponibilizados online e através de aplicativos } \\
\text { (apoio ao estudante) }\end{array}$ & \\
\hline & Oficina de Comunicação Não Violenta & \\
\hline & Encontro com os representantes discentes & $\begin{array}{l}\text { CAEP, CG, CAEG, CDDE, CDH, } \\
\text { DIRETORIA }\end{array}$ \\
\hline \multirow{8}{*}{ DOCENTES } & $\begin{array}{l}\text { Educação remota na saúde (e-disciplinas USP) - nível } \\
\text { intermediário - Turma } 1\end{array}$ & \multirow{7}{*}{ CDDE } \\
\hline & $\begin{array}{l}\text { Educação remota na saúde (e-disciplinas USP) - nível } \\
\text { intermediário - Turma } 2\end{array}$ & \\
\hline & $\begin{array}{l}\text { Estudo dirigido com apoio de tutores sobre educação } \\
\text { remota na saúde - atendimento individualizado }\end{array}$ & \\
\hline & $\begin{array}{l}\text { Educação remota na saúde - aprendizes em nível avan- } \\
\text { çado - Atendimento individualizado por demanda e com } \\
\text { tutoria de docente do CDDE }\end{array}$ & \\
\hline & $\begin{array}{l}\text { Vídeos sobre o e-disciplinas Moodle (funções relevantes) } \\
\text { com mais de } 20 \text { vídeos curtos disponibilizados no e-disci- } \\
\text { plinas para docentes da USP\# }\end{array}$ & \\
\hline & $\begin{array}{l}\text { Videos sobre funções importantes do Moodle disponibili- } \\
\text { zados no Moodle Extensão da USP para docentes de todas } \\
\text { as universidades brasileiras\# }\end{array}$ & \\
\hline & $\begin{array}{l}\text { Oficina (Invertida) sobre boas práticas na elaboração de } \\
\text { testes de múltipla escolha de ciências básicas aplicadas. }\end{array}$ & \\
\hline & Encontros pedagógicos online & CAEP \\
\hline \multirow{2}{*}{ FUNCIONÁRIOS } & $\begin{array}{l}\text { I Encontro de Funcionários da FMRP - Bem-estar no am- } \\
\text { biente de trabalho (ouvindo os representantes) }\end{array}$ & \multirow{2}{*}{ CDH, DIRETORIA } \\
\hline & $\begin{array}{l}\text { II Encontro de Funcionários da FMRP (Ouvindo as Chefias } \\
\text { Administrativas) }\end{array}$ & \\
\hline \multirow{4}{*}{$\begin{array}{l}\text { COMUNIDADE } \\
\text { FMRP }\end{array}$} & $\begin{array}{l}\text { Campanha "FMRP - Formando também melhores cida- } \\
\text { dãos" }\end{array}$ & \multirow{4}{*}{ CDH, DIRETORIA } \\
\hline & $\begin{array}{l}\text { Cartilha "Violência Interpessoal no trabalho: como identi- } \\
\text { ficar e combater o assédio moral e sexual" }\end{array}$ & \\
\hline & Campanha Somos todos Pacto & \\
\hline & $\begin{array}{l}\text { Grupo de Trabalho para construir Programa de Qualidade } \\
\text { de Vida e Satisfação no Trabalho }\end{array}$ & \\
\hline
\end{tabular}


Chegando ao final do primeiro semestre letivo, e visando um planejamento mais estruturado do segundo semestre, CAEP e CDH propuseram encontro com os representantes discentes nos diversos colegiados e Centros Acadêmicos. Numa atividade remota, foram utilizadas ferramentas dialógicas, com questões disparadoras, discussões em pequenos grupos e plenárias. $O$ registro visual das ideias foi realizado ao vivo, como potente sistematização dessa mediação (Figura 2).

Figura 2: Facilitação gráfica (registro visual) do encontro com Representações Discentes

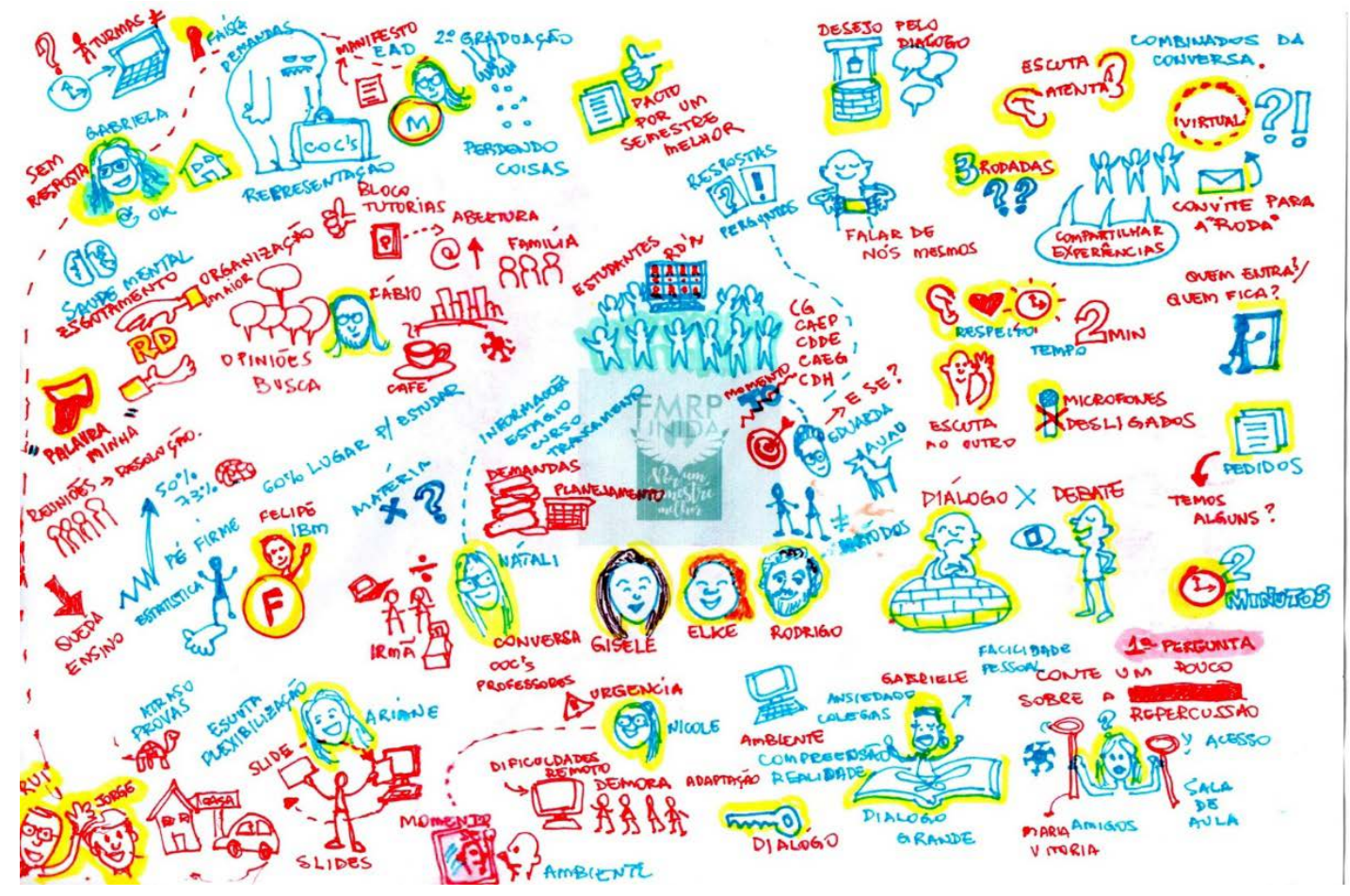

A escuta qualificada aos estudantes que ocupam espaços de mediação entre seus pares e as instâncias gestoras, ajudou a ampliar o diagnóstico sobre as suas necessidades e as possibilidades de acolhê-las, buscando melhorar a experiência de ensino-aprendizagem no segundo semestre.

A continuidade dos diálogos com as Representações Discentes se deu ao longo do segundo semestre, e, em atendimento a uma demanda específica, foi realizada oficina sobre as bases da Comunicação Não Violenta (CNV).

\section{AÇÕES VOLTADAS PARA OS PROFESSORES (CDDE, CAEP)}

O CDDE realizou uma enquete junto aos professores da FMRP-USP antes do final do pri- meiro semestre de 2020 e detectou uma grande motivação e disponibilidade, para participarem de atividades voltadas à capacitação docente para estratégias de ensino e avaliação do estudante mediadas por recursos tecnológicos, em especial o e-disciplinas da USP, e recursos do Google-Suite.

Deste modo, o CDDE desenhou um módulo de educação remota, mesclando princípios de aprendizagem de adultos, desenho de atividades instrucionais, estratégias de ensino e avaliação em ambientes de educação remota ou a distância. Reconhecendo a existência de diferenças entre os professores no que se refere às habilidades para o manejo de tecnologias da informação, propusemos estratégias diferentes: (1) uma voltada para iniciantes, com o auxílio de membros do corpo técnico administrativo da FMRP-USP com experiência no uso do e-disciplinas - Moo- 
dle, (2) um módulo intermediário para usuários com experiência prévia no uso do e-disciplinas e recursos do G-Suíte, e (3) um módulo para usuários avançados, que contariam com o apoio de docentes mais experientes e familiarizados no uso das ferramentas.

O módulo intermediário de educação remota para as profissões da saúde foi ofertado no final do primeiro semestre, de forma on line, envolvendo encontros síncronos, videoaulas, atividades assíncronas e plantões de dúvidas, para instrumentalizar e apoiar docentes no uso do edisciplinas. Houve grande procura e as 60 vagas foram preenchidas rapidamente. A empreitada foi tão importante, que menos de um mês depois o curso foi oferecido novamente para uma nova turma de docentes e preceptores. Além disso, vários materiais produzidos em forma de vídeos foram disponibilizados de maneira ampla e irrestrita por meio do canal do CDDE-FMRP-USP, no Youtube.

Aconteceram também intersecções com o CAEP, sobretudo na discussão e apoio à elaboração dos Planos de Ensino e Aprendizagem (PEA) das disciplinas e a realização de Encontros Pedagógicos (espaços troca de experiências e dúvidas entre pedagogos e docentes).

\section{AÇÕES VOLTADAS AOS FUNCIONÁ- RIOS (CDH, DIRETORIA FMRP)}

Tanto quanto estudantes e professores, os funcionários técnicos- administrativos e de apoio, sofreram alterações em suas rotinas de vida e de trabalho. Seguindo a mesma lógica e no melhor espírito do Pacto, a CDH propôs a realização de encontros com funcionários, para oferecer escuta qualificada e promover soluções compartilhadas. Foram realizados dois encontros no segundo semestre de 2020, sendo um primeiro com representantes de funcionários nos colegiados e departamentos; e um segundo com funcionários que ocupam posições de chefia. Foram utilizadas as mesmas estratégias do encontro com estudantes: questões disparadoras, discussão em pequenos grupos e plenárias.

A ideia de ouvir os funcionários e a integração CDH - Gestão (Diretoria e Assistências Técnicas) trouxe para a pauta da instituição a necessidade de um Programa Desenvolvimento Profissional e Bem-Estar no Trabalho. Foi constituído um grupo de trabalho permanente, com membros da $\mathrm{CDH}$ e representantes dos funcionários, para atuar na construção desse Programa, e seguir ao longo de 2021 oferecendo os encontros, para ouvir os funcionários e suas demandas, realizar diagnósticos mais precisos dos principais desafios e criar respostas a essas necessidades.

A CDH está trabalhando para oferecer oficinas de desenvolvimento profissional a partir de março de 2021, contando com os demais centros, para compor um portfólio para o Programa de Desenvolvimento Profissional. É o reconhecimento de que uma política clara de gestão de recursos humanos é necessária, no contexto de "cuidar" da comunidade.

Além das ações voltadas para os funcionários, e de sua participação nas ações para os estudantes, a $\mathrm{CDH}$ tem atuado para sensibilizar a comunidade para os temas dos direitos humanos, da equidade e do acolhimento à diversidade. Esteve à frente da Campanha "FMRP - Formando também melhores cidadãos", que com a \#nemumavez anunciou que atitudes violentas, sexistas, classistas, racistas, homofóbicas não são toleradas em nossa comunidade. A campanha, que foi lançada em 2019, teve a sua segunda etapa lançada em 2020, com importante repercussão na comunidade acadêmica, em meio aos desafios do distanciamento social, e do ensino e trabalho remotos. Como ação para reforçar o Pacto e os valores da FMRP, será lançada a Campanha "Somos todos PACTO", para abril de 2021.

Ainda no contexto do Pacto, está sendo preparada uma Cartilha sobre Assédios Moral e Sexual, para conscientizar as pessoas sobre essas duas importantes violações de direitos humanos, visando prevenir sua ocorrência, acolher vítimas e remediar situações já instaladas.

Todas as ações da $\mathrm{CDH}$, remetem aos valores e compromissos éticos da FMRP, e desta forma ao Pacto, não mais pensado como ações para "um semestre melhor", mas como compromissos que seguimos reafirmando. O Pacto nasceu no contexto da pandemia, mas nos remeteu à necessidade constante de aprimoramento das nossas relações, de investir em comunicação efetiva e em integração. 


\section{CONSIDERAÇÕES FINAIS}

Diante dos desafios colocados pela Pandemia, o Pacto teve a função inicial de resgatar e destacar os valores da instituição. As ações empreendidas tornaram possível à comunidade adquirir ferramentas para continuar realizando suas atividades, marcando o momento inicial da curva de aprendizagem para lidar com a educação remota emergencial, com o trabalho e com o distanciamento social. Entramos em 2021 mais preparados para enfrentar os desafios da crise sanitária.

Mesmo distantes fisicamente, como medida protetiva, surpreendentemente nos aproximamos e foi possível a união em prol de ações para garantir a formação profissional de qualidade para nossos estudantes, com equidade no acesso ao ensino, mantendo nossa saúde física e mental, à medida do possível, durante todo o ano de 2020.

A complexidade dos nossos desafios, daqui em diante, requer um envolvimento responsável da comunidade e das lideranças da FRMP, de modo a garantir as condições para que as atividades de ensino, pesquisa, extensão e gestão, transcorram com tranquilidade e segurança, levando aos meIhores resultados possíveis.

Além de fortalecer e qualificar a comunicação, foi preciso promover uma maior e melhor integração entre as diferentes Comissões, Centros e Setores Acadêmicos e Administrativos, para garantir à comunidade acesso fácil e direto aos recursos necessários e apoio, para atuar no novo cenário que se impôs em 2020, e segue nos desfiando em 2021.

Não sabemos ao certo o que nos espera na outra margem, mas temos certeza que, se permanecermos juntos e nos apoiarmos, chegaremos todos a este novo lugar, melhores do que éramos no momento da partida.

Reconhecer e acolher a diversidade numa unidade de ensino com as características da FMRP, significa compreender que soluções genéricas não atendem às necessidades de todos. São 3000 estudantes de graduação e pós-graduação, 329 professores e 418 funcionários, atuando num complexo de ensino, pesquisa e assistência. Os desafios apresentados em cada espaço foram singulares, e por isso pediram abordagens diferen- ciadas, para cada situação. Nesse sentido, cada ação proposta foi e continuará sendo desenhada considerando as peculiaridades e interfaces dos diferentes setores, para ampliar e qualificar a relação entre as pessoas, ainda que à distância.

Os desafios da educação integral e o compromisso de formar melhores cidadãos, circulam entre muitos discursos institucionais, contudo, é necessário que se materializem em ações e atitudes de todos aqueles que educam. Somente uma comunidade escolar, na concretude de seus desafios cotidianos, poderá estabelecer de forma significativa seus parâmetros de ação ética, por meio de uma discussão constante dos princípios gerais de nossa cultura e dos compromissos históricos de nossas instituições de ensino ${ }^{12}$.

A celebração de um Pacto centrado nos valores da Instituição, estreitou a parceria entre as comissões, centros e demais setores da FMRP, estudantes, professores e funcionários. E assim, seguimos unidos, procurando desenvolver atividades que façam sentido para toda a comunidade, e que nos ajudem a continuar enfrentando os desafios que estão por vir.

\section{REFERÊNCIAS}

1. CRUESP. Comunicado no. 03/2020 sobre a suspensão de aulas na USP, Unicamp e Unesp. Campinas, 13/03/2020. Disponível em: https://sites.usp.br/cruesp/comunicados/. Acessado em: 09/02/2021.

2. São Paulo. Coletiva de Imprensa realizada no dia 13/03/2020, realizada no Palácio dos Bandeirantes. Disponível em: https://www.youtube.com/watch?v=T0706JpdFqg Acessado em: 08/02/2021.

3.USP. Mensagens do Reitor à comunidade universitária sobre o coronavírus. 13, 16 e 20/03/2020. Disponível em: https://jornal.usp.br/institucional/mensagem-do -reitor-a-comunidade-universitaria-sobre-o-coronavirus/ Acessado em: 09/02/2021.

4. BRASIL. MEC. Portaria no 343, de 17 de março de 2020. Dispõe sobre a substituição das aulas presenciais por aulas em meios digitais enquanto durar a situação de pandemia do Novo Coronavírus - COVID-19. Disponível em: https://www.in.gov.br/en/web/dou/-/portaria-n343-de-17-de-marco-de-2020-248564376. Acessado em: 09/02/2021.

5. Santos, T. H. Ensino a distância é nova realidade para professores de graduação da USP. Jornal da USP, 2020. Disponível em: https://jornal.usp.br/universidade/ensino-a-distancia-e-nova-realidade-para-professores- 
de-graduacao-da-usp $\%$ E2 $\% 80 \% 8 \mathrm{~B} /$ Acessado em: 08/02/2021.

6. Cianflone ARL, Figueiredo JFC, Colares MFA. O Centro de Apoio Educacional e Psicológico (CAEP) da Faculdade de Medicina de Ribeirão Preto (USP). Medicina (Ribeirão Preto) 35: 392-6, 2002.

7. Panúncio-Pinto MP, Colares MFA. O estudante universitário: os desafios de uma educação integral. Medicina (Ribeirão Preto) 2015;48(3): 0-00.

8. Vygotsky, L. S. A Formação social da mente. São Paulo: Martins Fontes, 1989.
9. Markus, H. R; Kitayama, S. Culture and the self: implications for cognition, emotion and motivation. Psychological Review 98, 2, 224-253, 1991.

10. Morin, E. A cabeça bem-feita. $8^{a}$ ed. Rio de Janeiro: Bertrand Brasil, 2003.

11. Morin, E. Introdução ao pensamento complexo. $4^{\mathrm{a}}$ ed. Porto Alegre: Sulina, 2011.

12. Carvalho, J.S. Podem a ética e a cidadania ser ensinadas? Pró-Posições. Universidade Estadual de Campinas. FE. vol. (pp.157-168).13 set/dez 2002.

Editor:

Prof. Dr. Marcelo Riberto

Recebido: $30 / 04 / 2021$

Aprovado: 13/07/2021 